\title{
Does the headless roach learn to avoid?
}

\author{
RUSSELL M. CHURCH and NEIL D. LERNER \\ Brown University, Providence, Rhode Island 02912
}

\begin{abstract}
The headless roach has been identified as a relatively simple model system for the physiological analysis of instrumental learning. The basic observation is that an experimental roach that receives shock contingent upon a leg extension raises its leg more often and keeps it raised for a longer time than its yoked control roach. This evidence is inadequate to demonstrate learning, since these results are also consistent with a purely reactive model. The asymptotic results based on one such reactive model were similar to previously reported data.
\end{abstract}

In their review of current knowledge about the neurophysiology of learning, Thompson, Patterson, and Teyler (1972) described two research strategies: the recording of neural processes during the course of learning, and the study of "model systems." The first step in the model systems approach to the study of the neurophysiology of learning is to identify a simple animal (or restricted portion of the nervous system) which can be shown to learn in a manner that is similar to the learning of intact higher animals. Such a preparation could be ideal for subsequent physiological study.

\section{THE DEMONSTRATION OF LEARNING}

An important model system for the study of instrumental learning was developed by Horridge (1962a, b). His research has been widely cited as a demonstration that a cockroach (Periplaneta), even without head and brain, can learn to avoid electric shock. This demonstration suggests that the brain (the supra- and subesophageal ganglia removed by decapitation) is not necessary for learning, and that any ganglion might be sufficient for learning. The potential importance of this preparation for the analysis of the neural basis for learning was immediately recognized. The research has been widely cited in textbooks, and it has been replicated and extended by others. (See Alloway, 1973, and Eisenstein, 1972, for good reviews of the evidence.)

In the Horridge experiment, the experimental roach was suspended above a saline solution. It head and all but one of its legs were removed. The remaining leg was wired to a stimulator such that an electric shock would be delivered if the leg was extended; the shock circuit would be broken if the leg was lifted. Horridge noted that a reduction in the rate of shock received as a

This manuscript is an elaboration of a discussion at a workshop organized by R. F. Thompson and D. Jenness which was held at the Social Science Research Council in December 1973 (Teyler, Baum, \& Patterson, 1975). Dr. Kent Chapman provided us with the technical assistance and supplies necessary to observe the behavior of headless roaches during the course of avoidance training. David J. Getty helped us in the formal development of the model. N. D. Lerner is now at the National Bureau of Standards, Washington, D. C. function of training is not sufficient evidence of learning. Deterioration of the preparation, the effect of shock on nerves or muscles, and many other factors might lead to progressive changes in performance. Horridge (1962a) reported that he tried several methods to eliminate such factors, and finally decided on the yoked control design. Others have followed his lead (Eisenstein, 1972).

Figure 1 is a frequently reproduced diagram of the circuit used for avoidance training of an experimental headless cockroach and its yoked control. Each experimental roach was wired in series with a control roach such that the experimental and control subjects were shocked at precisely the same times. The experimental roach was shocked only when its leg was in the extended position; the control subject could be shocked when its leg was in any position. The point of the yoked control design is that both subjects receive shocks of the same intensity at the same times. (This is based on the assumption that the effective intensity of a shock to an extended leg which elicits large flexion response is no greater than that of a shock to an already flexed leg.) The only obvious difference between the two animals is that the experimental animal receives shock only when its leg is extended, while the control animal receives shock unrelated to its leg position or response.

In the second phase of the experiment, both the experimental animals and their yoked controls were treated like the experimental animals in the first phase. That is, the leg was shocked only when it was in the extended position. On the basis of a difference in the performance of the experimental subjects and their yoked controls in this phase, Horridge concluded that an association had been formed between the leg position and the instant of shock (classical conditioning). Others have emphasized the association between the downward movement and the occurrence of shock (punishment) or between the upward movement and the termination of shock (escape). The first problem, however, is to determine whether there is now sufficient evidence to conclude that any learning occurs in the headless cockroach. 
Two basic measures have been used during training: (a) the amount of time the leg is raised above a criterion height, and (b) the number of times the leg is raised above the criterion height. The results are that, during training, experimental animals make more responses than the yoked control animals, and they keep their legs raised for a higher percentage of the session.

These results have been readily accepted as evidence for learning for several reasons:

(1) The phenomenon is consistent with the nature of the insect nervous system. It is segmented into numerous ganglia, of which the brain is only one of the larger ones. A roach deprived of this ganglion can live for several weeks and move about its environment in a fairly normal manner. Walking and righting in headless insects indicates a high degree of local control by segmental ganglia. Thus, there is a reasonably high a priori probability of learning by a cockroach in the absence of a brain.

(2) The experimental design of the yoked control appears to be impeccable. The experimental and control subjects receive equivalent shock at exactly the same time. The only difference appears to be that the experimental subject receives shock contingent upon leg extensions, but the control subject receives shock unrelated to its response.

\section{A CRITICISM OF THE METHOD}

Differences between the performance of experimental subjects and their yoked control subjects do not necessarily demonstrate learning. Individual differences in reactivity to an event or even moment-tomoment differences in reactivity of a single subject to an event can lead to performance differences between the experimental group and its yoked control (Church, 1964). Even without any difference in the reactivity to an event, if behavioral changes occur in a probabilistic manner, it can be shown that performance differences between the two groups can emerge in the absence of any learning (Church \& Getty, 1972). Although this criticism has not been discussed in any of the insect learning literature, several reviews have described the pertinence of the argument to the question of whether or not the headless roach can learn (Kling \& Stevenson, 1970; Siegel, 1970). One application of the general criticism of the yoked control design to the headless roach experiment follows.

\section{Assumptions}

Two reasonable assumptions provide a theoretical account of the major finding that the experimental subjects avoid shock more successfully that the yoked controls during training. The specific values are given for illustrative purposes only, although they correspond roughly with our observations and some previously reported experimental results. The assumptions are: (a) When stimulated by electric shock, the leg withdraws

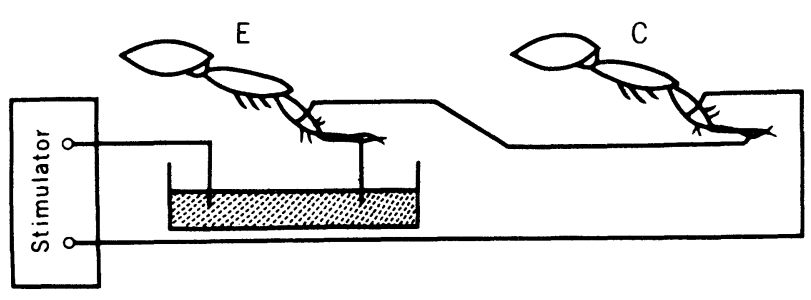

Figure 1. A diagram of the circuit used for avoidance training of an experimental headless roach (E) and its yoked control (C). After Horridge (1962b).

with a latency of $200 \mathrm{msec}$, and (b) when it is not stimulated, the leg returns to its extended position in an average of $10 \mathrm{sec}$. (More completely, with $\mathrm{p}=.5$, it falls $1 / 5$ of the total distance in each $1-\sec$ interval.)

\section{Procedure}

Two headless roaches are attached to a source of electrical shock, as shown in Figure 1. The experimental subject receives stimulation as soon as its leg is fully extended; the control subject receives stimulation when the experimental subject's leg is fully extended. Two measures of performance are recorded: the amount of time the leg of each subject is fully extended, and the number of responses per minute during training.

\section{Deductions}

On the basis of the assumptions, it is possible to calculate the expected number of responses per minute and the mean time the leg is in the fully extended position for subjects in the two conditions. The experimental leg always withdraws soon after it is fully extended, since it is stimulated at that time. The control leg can remain extended for substantial periods of time, since it will not withdraw again until the experimental leg is stimulated.

A computer simulation and direct calculation of the asymptotic results of this process led to the following conclusions:

Either by the measure of percent of time of successful avoidance or by the number of avoidance responses per minute, the experimental group performs at a higher level than the control group, despite the fact that no learning was assumed. With the values given in the statement of assumptions, the experimental subject makes about 6 extensions/min, since its withdrawal is rapid and its typical descent took about $10 \mathrm{sec}$. The control subject, on the other hand, makes about 3 extensions/min. The experimental subject holds its leg in the fully extended position about $1.2 \mathrm{sec} / \mathrm{min}$ $(6 \times 200 \mathrm{msec})$, while the control subject asymptotically (as the process gets out of phase) spends about 30 $\mathrm{sec} / \mathrm{min}$ in the extended position. Thus a purely reactive animal can appear to learn to avoid the shock. Table 1 shows the results from one experiment (Eisenstein, 1970) and the results from one simulation based on a 50-min session. 
Table 1

A Comparison of Observations of "Learning" by the Headless Roach (Data) with the Results of a Purely Reactive Model (Simulation) on Two Measures of Performance

\begin{tabular}{lccccc}
\hline & \multicolumn{2}{c}{$\begin{array}{c}\text { Proportion of } \\
\text { Time } \\
\text { Leg Extended }\end{array}$} & & \multicolumn{2}{c}{$\begin{array}{c}\text { Number of } \\
\text { Responses } \\
\text { Per Minute }\end{array}$} \\
\cline { 2 - 3 } \cline { 5 - 6 } & Data * & $\begin{array}{c}\text { Sim- } \\
\text { ulation }\end{array}$ & & Data & $\begin{array}{c}\text { Sim- } \\
\text { ulation }\end{array}$ \\
\hline $\begin{array}{l}\text { Experimental } \\
\text { Control }\end{array}$ & .09 & .02 & 7 & 6 \\
& .54 & .49 & & 3 & 3 \\
\hline
\end{tabular}

*From Figure 3 of Eisenstein (1970)

\section{DEVELOPMENT OF A TEST FOR LEARNING}

Because of the serious difficulty in interpreting the results during training, Horridge (1962b) restricted his quantitative description to a subsequent testing session in which both animals were treated alike, in the manner of the experimental subject in the training phase. He had no confidence that a comparison between these conditions during training was a valid indication of associative learning. His criticism was as follows:

"As the (experimental) animal holds its leg up progressively more and more, the intervals between shocks to the (control) animal's leg increase to several minutes and the (control) animal no longer holds up its leg. A demonstration of associative learning could possibly be based on this difference in position, which frequently arises because during the later part of the training of the (experimental) leg there are an insufficient number of shocks reaching the (control) leg to give it necessary stimulus to maintain a raised posture. However, it is not evident that such comparison is valid while the stimulus is switched on. Although there are no mechanical restraints on either leg, the (experimental) leg is liable to receive shocks and so is not free to go below a certain position. The (experimental) leg, therefore, has two distinct states, when being shocked and when not, depending on its position, and it's not obvious whether its position at all moments can be fairly contrasted with the position of the (control) leg" (Horridge, 1962b). In other words, the experimental situation is devised so that the experimental subject must do well during training: shock drives the leg up. This early caveat has sometimes been ignored (e.g., Pritchatt, 1968).

Several investigators have found that the experimental subjects received less shock than the control subjects even during the testing sessions in which they were both given the experimental treatment (Horridge, 1962b; Eisenstein, 1970). This demonstrates that the prior treatment has a differential effect, but it does not demonstrate that the experimental animals had learned anything. A cursory examination of Table 1 shows a major difference between the two conditions: The experimental legs were activated at about twice the rate of the control legs. As a result of any factor related to the rate or number of reactions previously elicited by shock (e.g., sensitization, fatigue), the animals might show differential behavior in a test situation without having learned anything about the contingency between response and shock. Furthermore, if the effectiveness of a shock were a function of the position of the leg, differential performance might occur.

There are three additional technical difficulties with some experiments designed to demonstrate learning in the headless roach. (a) The exact placement of the movable leg with respect to the criterion height is critical to the level of performance, and it is not easy to do in a repeatable manner. To eliminate this potential source of bias, animals should be attached to the apparatus by someone who does not know whether an animal is in the experimental or control treatment. (b) Training sessions are often reported to be of variable length. If training continues until the experimental subject has its leg raised, and if there is a tendency for an animal to continue doing what it has recently been doing, then a person could falsely conclude that a treatment difference existed. (c) In some cases, data are reported from only a small subset of the animals actually tested. When the reported results are only of borderline significance, such selectivity may affect the conclusions.

If the yoked control design is inadequate to demonstrate learning in a simple model system, is there another control group which is appropriate? There is reason to be skeptical of the automatic use of any single control group, since no one alone adequately rules out all the reasonable alternatives to learning (Teyler et al., 1975). Instead of depending upon a single control condition, it is necessary for investigators to use different control groups to rule out specific reasonable alternatives. This approach can never establish with certainty that learning is occurring in a particular model system, but when all the plausible alternatives have been ruled out, our confidence in a conclusion (e.g., the headless roach can learn to avoid) will be greatly increased.

\section{APPENDIX}

\section{Calculation of the Asymptotic Results}

Our first assumption is that if the leg of the experimental subject was down at time $t$, (i.e., shock occurred), the leg of the experimental subject and its yoked control subject will be up at time $t+1$, where each unit of time is $200 \mathrm{msec}$. Our second assumption is that if the leg of the experimental subject was up at time $t$, then $p$ is the constant probability that a leg will remain up at time $t+1$, and $q=1-p$ is the probability that $a$ leg will be down at time $t+1$. Our third assumption is that the value of $p$ was the same for the experimental and control subject.

Table A shows the four states of the system, and the asymptotic probability of each of the states. The system is in State 1 if both legs are up, in State 2 if the experi- 
Table A

The Four States

\begin{tabular}{ccll}
\hline State & $\begin{array}{c}\text { Position of } \\
\text { Legerimental } \\
\text { Leg }\end{array}$ & $\begin{array}{c}\text { Position of } \\
\text { Control } \\
\text { Leg }\end{array}$ & $\begin{array}{l}\text { Asymptotic } \\
\text { Probability }\end{array}$ \\
\hline $\mathrm{S}_{1}$ & $\mathrm{Up}$ & $\mathrm{Up}$ & $1 /(2+\mathrm{pq})$ \\
$\mathrm{S}_{2}$ & $\mathrm{Up}$ & Down & $\mathrm{p} /(2+\mathrm{pq})$ \\
$\mathrm{S}_{3}$ & Down & Up & $\mathrm{pq} /(2+\mathrm{pq})$ \\
$\mathrm{S}_{4}$ & Down & Down & $\mathrm{q} /(2+\mathrm{pq})$ \\
\hline
\end{tabular}

Table B

Matrix of Transition Probabilities

\begin{tabular}{|c|c|c|c|c|c|}
\hline & & \multicolumn{4}{|c|}{$t+1$} \\
\hline \multirow{5}{*}{$t$} & & $S_{1}$ & $\mathrm{~S}_{2}$ & $\mathrm{~S}_{3}$ & $\mathrm{~S}_{4}$ \\
\hline & $\mathrm{S}_{1}$ & $\mathrm{p}^{2}$ & $\mathrm{pq}$ & $\mathrm{pq}$ & $\mathrm{q}^{2}$ \\
\hline & $\mathrm{S}_{2}$ & 0 & $\mathrm{p}$ & 0 & $\mathrm{q}$ \\
\hline & $\mathrm{S}_{3}$ & 1 & 0 & 0 & 0 \\
\hline & $\mathrm{S}_{4}$ & 1 & 0 & 0 & 0 \\
\hline
\end{tabular}

mental leg is up and the control leg is down, etc. The asymptotic probabilities were calculated as follows:

The matrix of transition probabilities (P) shown in Table $B$ was defined on the basis of the assumptions above. For example, the probability that a system in State 1 will remain in State 1 is the probability that both legs that are up remain up $\left(\mathrm{p}^{2}\right)$; the probability that a system will change from State 2 to State 1 is zero since a control leg cannot rise unless the experimental leg is raised.

A probability vector, $\alpha$, describes the distribution of pairs of subjects in the four states at any time. To find the distribution of pairs of subjects on the next trial, one

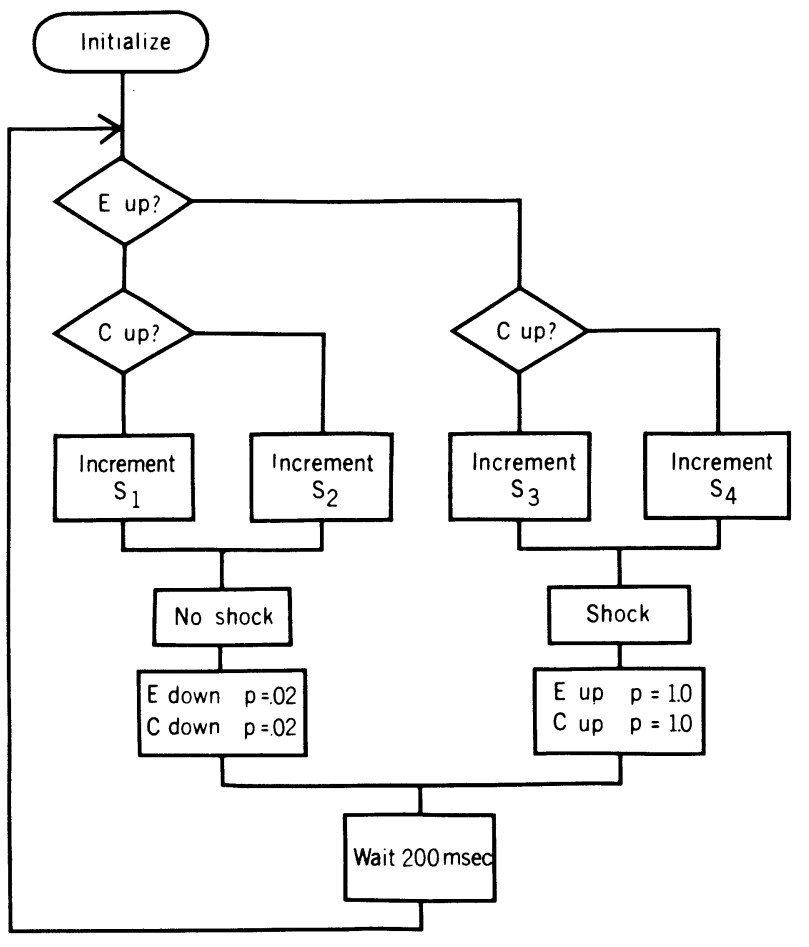

Figure 2. Flow diagram of the simulation. simply multiplies this probability vector by the matrix $P$ of Table B. The problem is to find the values of $\alpha$ such that $\alpha=\alpha \mathrm{P}$. This is the asymptotic distribution shown in Table $A$.

The probability that an experimental leg is up at asymptote is $\mathrm{p}\left(\mathrm{S}_{1}+\mathrm{S}_{2}\right)=(1+\mathrm{p}) /(2+\mathrm{pq})$. As $\mathrm{p} \rightarrow 1$, this probability approaches 1.0 . The probability that a control leg is up at asymptote is $\mathrm{p}\left(\mathrm{S}_{1}+\mathrm{S}_{3}\right)=$ $(1+\mathrm{pq}) /(2+\mathrm{pq})$. As $\mathrm{p} \rightarrow 1.0$, this probability approaches 0.5 .

A similar result was obtained by a computer simulation. The simulation was based upon the flow diagram shown in Figure 2. The current state of the system was recorded (State 1 if both experimental and control roaches had legs up, etc., as defined in Table A). If the experimental roach (E) had its leg up, the probability that its leg would go down in the current time period was .02 , and the probability that the leg of the yoked control subject (C) would go down in the current time period was also .02. If the experimental roach had its leg down, shock occurred, and both the experimental and control legs were raised. After a 200-msec delay, the next time period began. The result of the simulation is shown in Table 1 .

\section{REFERENCES}

Alloway, T. Learning in insects except Apoidea. In W. C. Corning, J.A. Dyal, \& A. O. D. Willows (Eds.), Invertebrate learning: Arthropods and gastropod mollusks (Vol. 2). New York: Plenum, 1973.

Church, R. M. Systematic effect of random error in the yoked control design. Psychological Bulletin, 1964, 62, 122-131.

Church, R. M., \& Getry, D. J. Some consequences of the reaction to an aversive event. Psychological Bulletin, 1972, 78, 21-27.

EISENSTEIN, E. M. A comparison of activity and position response measures of avoidance learning in the cockroach, $P$. americana. Brain Research, 1970, 21, 143-147.

Eisenstein, E. M. Learning and memory in isolated insect ganglia. In J. E. Treherne, M. J. Berridge, \& V. B. Wiggleworth (Eds.), Advances in insect physiology (Vol. 9). New York: Academic Press, 1972.

HorRIDGE, G. A. Learning of leg position by headless insects. Nature, 1962, 193, 697-698. (a)

HoRRIDGE, G. A. Learning of leg position by the central nerve cord in headless insects. Proceedings of the Royal Society, 1962, 157, 33-52. (b)

Kling, J. W., \& Stevenson, J. G. Habituation and extinction. In G. Horn \& R. A. Hinde (Eds.), Short-term changes in neural activity and behavior. Cambridge: Cambridge University Press, 1970.

Pritchatt, D. Avoidance of electric shock by Periplaneta americana. Animal Behaviour, 1968, 16, 178-185.

SIEgel, S. The psychobiology of conditioning. In M. Marx (Ed.), Learning: Interactions. London: Macmillan, 1970.

Teyler, T. J., Baum, W. M., \& Patterson, M. M. Behavioral and biological issues in the learning paradigm. Physiological Psychology, 1975, 3, 65-72.

Thompson, R. F., Patterson, M. M., \& Teyler, J. J. The neurophysiology of learning. In Annual Review of Psychology (Vol. 23). Palo Alto: Annual Reviews, 1972. 